2010

\title{
Maximum Power from a Solar Panel
}

Michael Miller

University of South Florida

\author{
Advisors: \\ Gerald Hefley, Mathematics and Statistics \\ Scott Campbell, Chemical \& Biomedical Engineering \\ Problem Suggested By: Scott Campbell
}

Follow this and additional works at: https://digitalcommons.usf.edu/ujmm

Part of the Mathematics Commons

UJMM is an open access journal, free to authors and readers, and relies on your support:

Donate Now

\section{Recommended Citation}

Miller, Michael (2010) "Maximum Power from a Solar Panel," Undergraduate Journal of Mathematical Modeling: One + Two: Vol. 3: Iss. 1, Article 10.

DOI: http://dx.doi.org/10.5038/2326-3652.3.1.22

Available at: https://digitalcommons.usf.edu/ujmm/vol3/iss1/22 


\title{
Maximum Power from a Solar Panel
}

\begin{abstract}
Solar energy has become a promising alternative to conventional fossil fuel sources. Solar panels are used to collect solar radiation and convert it into electricity. One of the techniques used to maximize the effectiveness of this energy alternative is to maximize the power output of the solar collector. In this project the maximum power is calculated by determining the voltage and the current of maximum power. These quantities are determined by finding the maximum value for the equation for power using differentiation. After the maximum values are found for each time of day, each individual quantity, voltage of maximum power, current of maximum power, and maximum power is plotted as a function of the time of day.
\end{abstract}

Keywords

Solar Power, Photovoltaic Current, Maximum Voltage

Creative Commons License

(c) (i)(9)

This work is licensed under a Creative Commons Attribution-Noncommercial-Share Alike 4.0 License.

\section{Erratum}

This article was previously called Article 22. 


\section{TABLE OF CONTENTS}

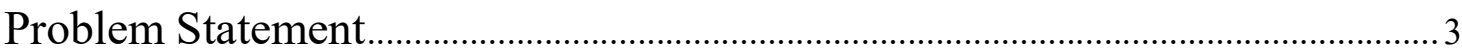

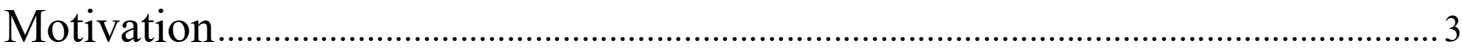

Mathematical Description and Solution Approach ................................................. 4

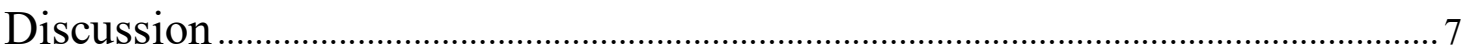

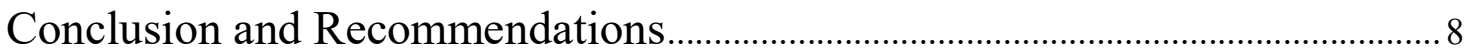

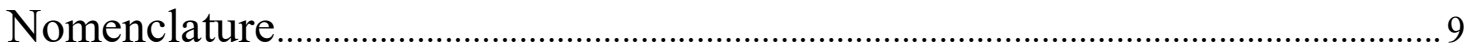

References

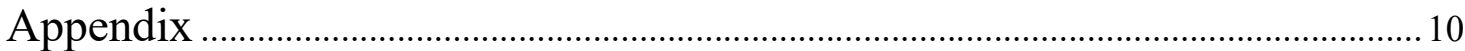




\section{PROBLEM STATEMENT}

The current voltage relationship ( $I-V$ curve) for a particular photovoltaic solar module is represented by

$$
I=I_{P V}-I_{0}\left(e^{b V}-1\right)
$$

where $I_{0}=4.1 \times 10^{-5}$ amps and $b=0.5$. The photovoltaic current $I_{P V}$ is variable and depends on the amount of solar radiation, which in turn, depends on the time of day. For this solar module,

$$
I_{P V}=2.54 \sin \left[\frac{\pi}{12}(t-6)\right]
$$

where $I_{P V}$ is in amps and $t$ represents the hour of the day ( $t=6$ corresponds to sunrise and $t=12$ to solar noon). A controller has been designed to make the module operate at its maximum power where

$$
P=I V
$$

is a maximum. The current and voltage that yield the maximum power will vary with the time of day.

We would like to have graphs of how the maximum power, current, and voltage of the module changes with time. Plot $P_{\max }, I$, and $V$ versus time from $t=6$ to $t=12 \mathrm{hrs}$.

\section{Motivation}

In the $21^{\text {st }}$ century there has been a significant shift away from pursuing conventional fossil fuel energy sources. Research has shown they are responsible for a host of environmental problems such as, releasing carcinogenic substances into the air and emitting greenhouse gases 
into the atmosphere (EPA). Another reason why this shift has occurred is because conventional sources of fossil fuels are finite and nonrenewable. Once all the remaining reserves begin to dwindle, they will no longer be able to keep up with the current demand of energy consumption.

As a result of this impending energy crisis, several renewable energy sources have been explored as alternatives to fossil fuels. One of these promising sources is solar energy, the collection of solar radiation via solar panels which convert the energy into electricity. Solar energy is a promising alternative energy source because it is readily available and inexhaustible.

There has recently been significant growth in the area of solar cell technology (Emspak). Ever since the discovery of the photovoltaic effect in the late 1830 s and the invention of the silicon solar cell in the 1950s, engineers have worked on ways to better harvest solar energy (Kuwano, Okamoto and Tsuda). Some of these methods range from improving the design of the solar cells that gather the solar radiation, such as reducing the size and thickness of the solar cell, to designing modules that operate solar panels at their maximum power output. The aim of this project is to identify the maximum power achieved by a solar module given certain parameters.

\section{MATHEMATICAL DESCRIPTION AND SOLUTION APPROACH}

A preliminary objective to solving the problem is to identify all the necessary equations. The first equation that needs to be identified is the equation that models the relationship between voltage and current for this module given by:

$$
I=I_{P V}-I_{0}\left(e^{b V}-1\right)
$$

which from now on will be referred to as Equation 1. $I_{P V}$ in (1) is a variable quantity known as photovoltaic current that can be modeled over time $t$ by 


$$
I_{P V}=2.54 \sin \left[\frac{\pi}{12}(t-6)\right]
$$

It is now necessary to considertheformula that relates current and voltage to power. This relationship is given by

$$
P=I V
$$

where $P$ is power, $I$ is current, and $V$ is voltage.

Now that the governing equations (1)-(3) are identified we apply the following methodology. First we determine the photovoltaic current $I_{P V}$ at each time $t$ from $t=6$ to $t=12$ using (2). Next we will calculate the voltage of max power. In order to do this, we substitute(1)into(3) and get

$$
P=I V=\left(I_{P V}-I_{0}\left(e^{b V}-1\right)\right) V
$$

The derivative of $P$ with respect to $V$ helps to identify the maximum power with regard to voltage. We compute

$$
\frac{d P}{d V}=\left(I_{P V}-I_{0}\left(e^{b V}-1\right)\right)-\left(I_{0} b e^{b V}\right) V=I_{P V}+I_{0}-I_{0} e^{b V}(1+b V) .
$$

Setting (5) to zero yields potential power maximums, i.e.,

$$
I_{P V}+I_{0}-I_{0} e^{b V}(1+b V)=0 .
$$

We now make use of the facts that $b=1 / 2, I_{0}=4.1 \times 10^{-5} \mathrm{amps}$, and (2) to write (6) as 


$$
\frac{2.54}{4.1 \times 10^{-5}} \sin \left[\frac{\pi}{12}(t-6)\right]=e^{V / 2}\left(1+\frac{V}{2}\right)-1 \text {. }
$$

Some values which satisfy (7) are listed in the table below (Fig. 2). We used Wolfram Alpha (Wolfram Alpha LLC) to achieve the numerical results, but Newton's Method could also be used to find $V$ at fixed times $t$ (see Appedix for computer code).

Comparing both side of (7), the fact that $\sin \left[\frac{\pi}{12}(t-6)\right]$ is increasing for $t$ between 6 and 12 implies that $e^{V / 2}\left(1+\frac{V}{2}\right)$ is increasing over the same range. Further, both $e^{V / 2}$ and $\left(1+\frac{V}{2}\right)$ are strictly increasing functions, so $V$ must be increasing as $t$ increases. Therefore the power maximizing voltage $V$ occurs when $t$ is maximized, i.e., $t_{\max }=12$. From the table in Figure 2, power is maximized when $V_{\max }=17.512$.

Knowing the time and voltage for which power is maximized allows us to use (1), (2) and (3) to compute

$$
P_{\max }=\left(\left(2.54 \sin \left[\frac{\pi}{12}\left(t_{\max }-6\right)\right]\right)-I_{0}\left(e^{V_{\max } / 2}-1\right)\right) V_{\max } \approx 39.92 \mathrm{~W} .
$$

\begin{tabular}{|cc|}
\hline $\boldsymbol{t}$ & $\boldsymbol{V}_{\max }$ \\
\hline $\mathbf{6}$ & 0.000 \\
\hline $\mathbf{7}$ & 15.076 \\
\hline $\mathbf{8}$ & 16.259 \\
\hline $\mathbf{9}$ & 16.885 \\
\hline $\mathbf{1 0}$ & 17.252 \\
\hline $\mathbf{1 1}$ & 17.450 \\
\hline $\mathbf{1 2}$ & 17.512 \\
\hline
\end{tabular}

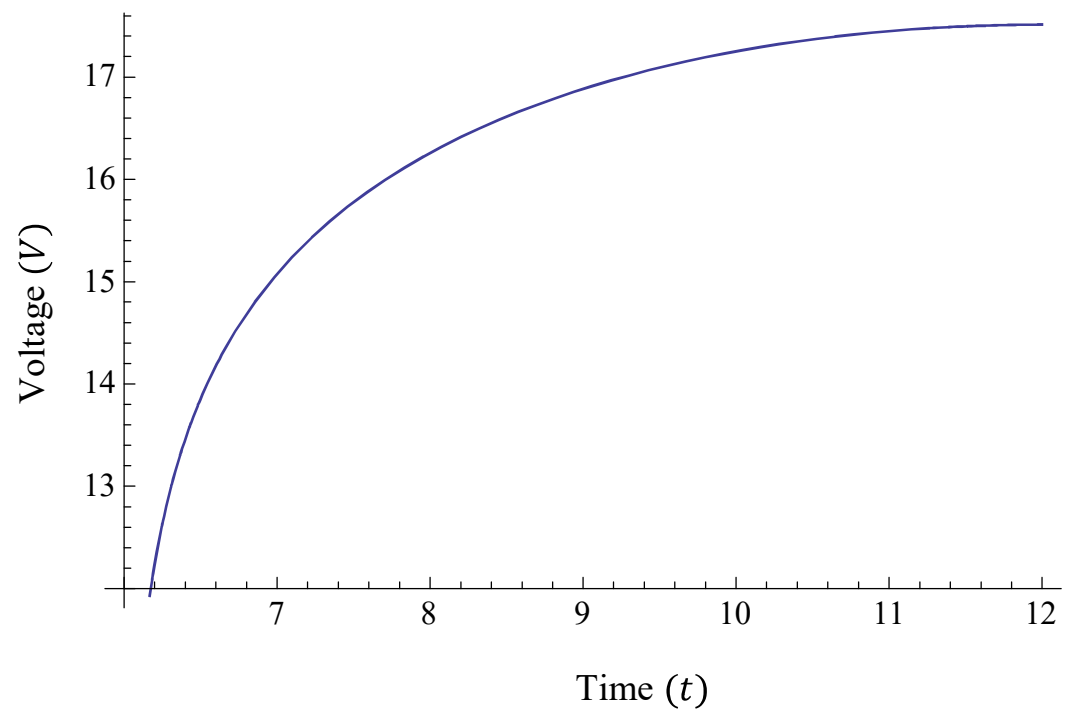

Figure 2: Voltage $V_{\max }$ which yields the maximum power for a solar cell at time $t$. 
The plot of the solar cell's power over time and voltage is presented below. The figure clearly illustrates that the power reaches a maximum of $P_{\max }=39.92 \mathrm{~W}$ at time $t_{\max }=12$ (solar noon) and voltage $V_{\max }=17.512 \mathrm{~V}$.

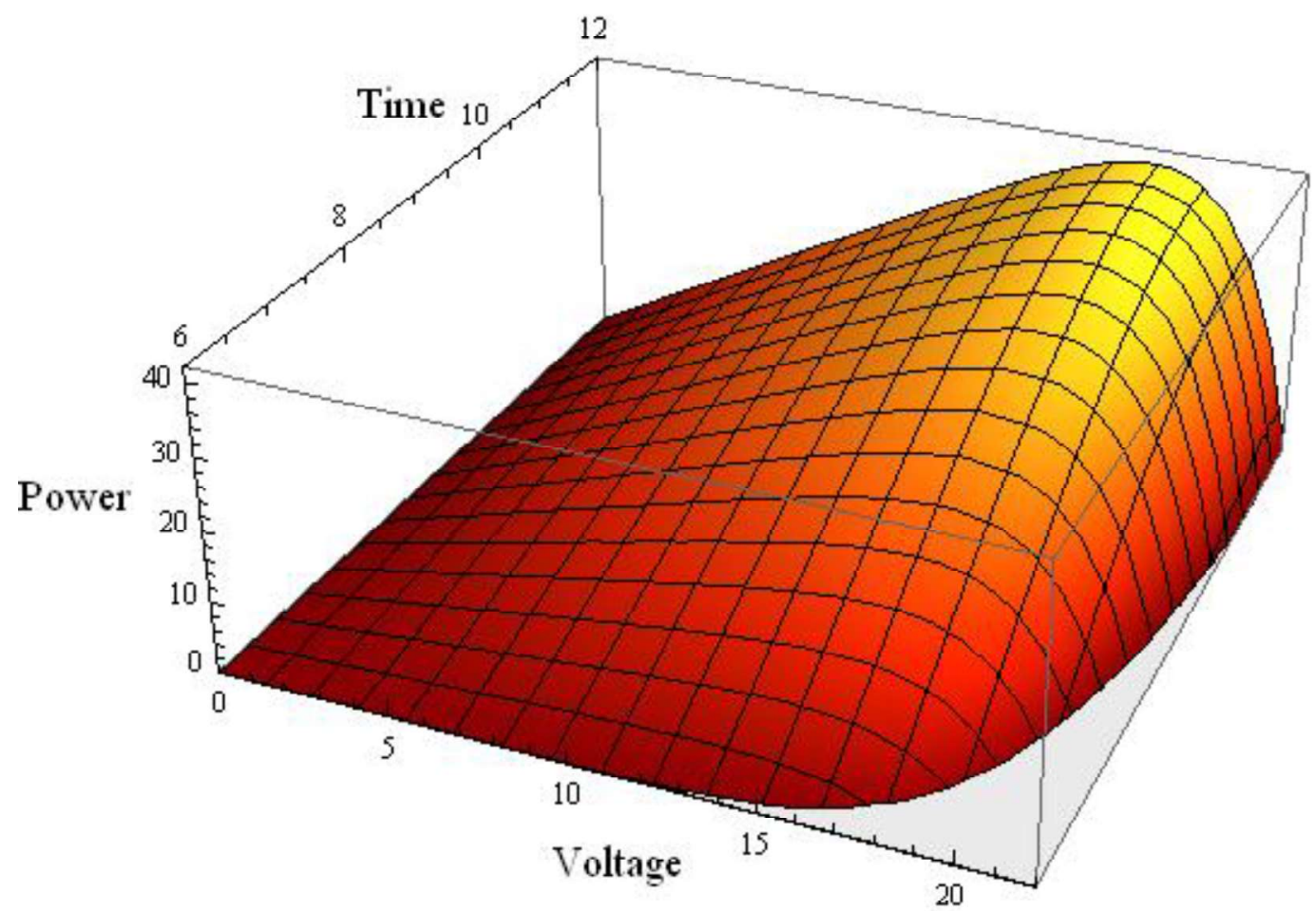

Figure 2: Plot of Power (W) produced by the solar cell over the range of time (Hr) and Voltage (V).

\section{DISCUSSION}

Figure 2 indicates that the maximum power increases as time progresses. Figures 1 and 2 illustrate a similar trend with the voltage of max power and the current of maximum power.

These results are not surprising since the times $t=6$ through $t=12$ correspond to the period from sunrise to solar noon. 
These results show both the strength and weaknesses of using solar energy as viable alternative energy. Although the energy is essentially provided for "free" by the sun, the maximum power output is limited by the time of day which the solar cells collect solar radiation. Contemplating this limitation, it was realized that the current focus of solar technology is on designing devices that collect solar radiation within the earth's atmosphere. This focus effectively limits the spectrum of energy from which the devices can generate electricity. This hurdle can be overcome if less emphasis is place on solar devices within our atmosphere and more on devices that can collect solar energy outside the earth's atmosphere.

\section{CONCLUSION AND RECOMMENDATIONS}

The objective of this project was to determine the maximum power, voltage of maximum power, and current of maximum power and plot these three quantities with respect to time. This project helped demonstrate the effectiveness of using the derivative of a function to determine the maximum value of that function. The parameters given for the solar module in this project were used to derive a relationship between power and voltage. In order to further solar cell technology, it would benefit engineers involved in designing new solar technologies to consistently maximize the power output of current solar devices in order to expedite the process into more effective solar technologies.

Some recommendations to improve the optimization of a solar cell's power output would be to use smaller intervals between the time values used when plotting maximum power in order to get a more accurate picture of the solar cells behavior in smaller and larger periods of time. In addition, it might be suggested that further research should be directed towards finding a way to collect solar radiation from a solar cell in orbit and effectively transmitting the electricity generated back to earth wirelessly. 
NOMENCLATURE

\begin{tabular}{|cll|}
\hline Symbol & Description & Units \\
\hline$I$ & Current & Amps \\
\hline$P$ & Power & Watts \\
\hline$V$ & Voltage & Volts \\
\hline
\end{tabular}

\section{REFERENCES}

Emspak, Jesse. "Chasing Rainbows: Full-Spectrum Photovoltics." Scientific American (2008).

EPA, US. Inventory of U.S. Greenhouse Gas Emissions and Sinks: 1990-1998. EPA 236-R-0001. Washington, D.C.: US EPA, 2000.

Kuwano, Y., S. Okamoto and S. Tsuda. "Semiconductor Devices Save the Earth: Solar Cells." Electron Devices Meeting. International: Technical Digest, 1992. 3-10.

Larson, Ron, Robert Hostetler and Bruce Edwards. Calculus. 8th Edition. Boston, MA: Houghton Mifflin Company, 2005.

Wolfram Alpha LLC. Wolfram Alph. 2010. <http://www.wolframalpha.com/>. 


\section{APPENDIX - MATHEMATICA CODE}

Mathematica code used on Wolfram Alpha to solve

$$
\frac{2.54}{4.1 \times 10^{-5}} \sin \left[\frac{\pi}{12}(t-6)\right]=e^{V / 2}\left(1+\frac{V}{2}\right)-1
$$

at time $t=8$.

In[1]: Solve $\left[\left(2.54 /\left(4.1 * 10^{\wedge}-5\right)\right)(\operatorname{Sin}[(\backslash[\mathrm{Pi}] / 12)(8-6)])==\operatorname{Exp}[\mathrm{V} / 2](1+\mathrm{V} / 2)-1, \mathrm{~V}\right]$

Out [1]: $\quad V=16.259$

Mathematica code used on to plot the power function (Figure 2).

In[2]: $\operatorname{Plot} 3 \mathrm{D}\left[\mathrm{v}\left(2.54 * \operatorname{Sin}[(\backslash[\mathrm{Pi}] / 12)(\mathrm{t}-6)]-\left(4.1 * 10^{\wedge}(-5)\right)(\operatorname{Exp}[\mathrm{v} / 2]-\right.\right.$

1)), $\{v, 0,23\},\{t, 6,12\}]$ 